\title{
Tourniquet use in routine primary total knee arthroplasty is associated with a higher transfusion rate and longer postoperative length of stay: a real-world study
}

Hong $\mathrm{Xu}^{1 \dagger}$, Jingli Yang ${ }^{2+}$, Jinwei $\mathrm{Xie}^{1+}$, Zeyu Huang ${ }^{3}$, Qiang Huang ${ }^{3}$, Guorui $\mathrm{CaO}^{3}$ and Fuxing Pei ${ }^{3^{*}}$ (i)

\begin{abstract}
Background: In an enhanced recovery after surgery program, a growing number of orthopedists are reconsidering the necessity of tourniquet use in total knee arthroplasty (TKA). However, the impact of tourniquet use on transfusion rate and postoperative length of stay (PLOS) in TKA remains controversial. Therefore, we carried out a study to investigate the effect of tourniquet application in routine primary TKA on transfusion rate and PLOS.

Methods: We analyzed data from 6325 patients who underwent primary unilateral TKA and divided them into two groups according to whether a tourniquet was applied during the procedure, and a tourniquet was used in 4902 and not used in 1423. The information for transfusion and PLOS was extracted from patients' electronic health records, and the data were analyzed with logistic and linear regression analyses.

Results: Following TKA, the transfusion rate and PLOS were $14.52 \%$ and $7.72 \pm 3.54$ days, respectively, in the tourniquet group, and $6.47 \%$ and $6.44 \pm 3.48$ days, respectively, in the no-tourniquet group. After adjusting for the different related variables, tourniquet use was significantly correlated with a higher transfusion rate (risk ratio $=$ 1.888, 95\% confidence interval $(C I) 1.449-2.461, P<0.001$ ) and a longer PLOS (partial regression coefficient $(B)=$ $0.923,95 \% \mathrm{Cl} 0.690-1.156, P<0.001)$.

Conclusions: Our findings suggested that tourniquet use in routine primary TKA was related to a higher transfusion rate and a longer PLOS. The impact of tourniquet use on transfusion rate and PLOS should be taken into account in clinical practice.
\end{abstract}

Keywords: Tourniquet, Knee, Arthroplasty, Transfusion, Length of stay

Total knee arthroplasty (TKA) is considered one of the most successful orthopedic surgical treatments for end-

\footnotetext{
* Correspondence: peifuxingwestchina@163.com

${ }^{\dagger} H o n g \mathrm{Xu}$, Jingli Yang and Jinwei Xie, co-first authors, these three authors contributed to this article equally.

${ }^{3}$ Department of Orthopaedic surgery, West China Hospital, Sichuan University, No.37, Guoxue Road, Wuhou district, Chengdu 610041, China Full list of author information is available at the end of the article
}

stage knee diseases because it can relieve pain, improve lower limb function, and improve patients' quality of life $[1,2]$. Tourniquets have been used in TKA since the procedure was first introduced [3, 4]. Until 2011, tourniquets were used in approximately $90 \%$ of the 12,048 primary TKAs performed in Sweden [5]. Proponents of tourniquet use in TKA believe that it can reduce intraoperative bleeding volume (which potentially offers a

(c) The Author(s). 2020 Open Access This article is licensed under a Creative Commons Attribution 4.0 International License, which permits use, sharing, adaptation, distribution and reproduction in any medium or format, as long as you give appropriate credit to the original author(s) and the source, provide a link to the Creative Commons licence, and indicate if changes were made. The images or other third party material in this article are included in the article's Creative Commons. licence, unless indicated otherwise in a credit line to the material. If material is not included in the article's Creative Commons licence and your intended use is not permitted by statutory regulation or exceeds the permitted use, you will need to obtain permission directly from the copyright holder. To view a copy of this licence, visit http://creativecommons.org/licenses/by/4.0/. The Creative Commons Public Domain Dedication waiver (http://creativecommons.org/publicdomain/zero/1.0/) applies to the data made available in this article, unless otherwise stated in a credit line to the data. 
relatively bloodless operating field), decreases the operative time, and, perhaps most importantly, ensures a better cementation result that leads to effective and longterm implant fixation [6, 7]. However, opponents of tourniquets propose that their use in TKA can lead to skin blistering, soft-tissue damage, muscle atrophy, ischemia-reperfusion injury (which contributes to postoperative pain), hematoma at the thigh, and weakness of the quadriceps; moreover, tourniquet use can hamper early mobilization and slow down postoperative rehabilitation [8-10].

In addition, the development of enhanced recovery after surgery (ERAS) programs, especially the extensive use of tranexamic acid (TXA) (an effective and safe antifibrinolytic drug) in the perioperative period and a controlled hypotension technique during the procedure, has significantly decreased both total blood loss and intraoperative bleeding volume, and offers a blood-free operating field in TKA [11-13]. Hence, a growing number of orthopedists are questioning the validity of tourniquet use in TKA [5, 14].

Although numerous studies have assessed the impact of tourniquet use on transfusion rate and postoperative length of stay (PLOS) in TKA, tourniquet application remains controversial because most of the current literature includes limited sample sizes and wide diversity, often producing inconsistent conclusions $[5,15,16]$. Therefore, we conducted a retrospective cohort study based on a large dataset to identify (1) whether tourniquet use affect the postoperative transfusion rate, and (2) whether tourniquet use is correlated with longer PLOS after routine primary TKA (simple cases without severe varus or valgus deformity, that means the hipknee-ankle angle $<165^{\circ}$ or $>195^{\circ}$ ).

\section{Materials and methods Data source}

A prospective multicenter study, which was sponsored by the Ministry of Health of the People's Republic of China (project number: 201302007) and enrolled in 26 university teaching hospitals in China (included 10 national and 16 regional hospitals), was carried out to assess the efficacy and safety of perioperative management measure and improve the development enhance recovery after surgery of TKA and total hip arthroplasty in China from 2013 to 2016. The large database generated from the study was analyzed secondarily for evaluating the effect of tourniquet use in TKA on transfusion rate and PLOS. Whether to use a tourniquet during surgical procedure in TKA was determined by the leader of each medical team. The transfusion criteria of allogeneic blood for each patient followed the specification for clinical transfusion technology issued by Ministry of Health of the People's Republic of China in June 2000. Those were (1) hemoglobin level $<70 \mathrm{~g} / \mathrm{L}$ and (2) according to the anemia degree of the patient, cardiopulmonary compensatory function, whether or not metabolic rate increased and age and other factors when hemoglobin level between 70 and $100 \mathrm{~g} / \mathrm{L}$. In addition, the PLOS was defined as the date of discharge minus the date of surgery. The database analyzed in this study included patient-level hospital discharge data provided by enrolled 26 hospitals. The accuracy and completeness of the data were inspected and verified carefully by comparison with information from hospital electronic record. This study was deemed exempt by the hospital's institutional review board. And all patients gave their informed consent.

\section{Study population}

The Clinical Modification procedure codes of the International Classification of Diseases, Tenth Revision (IDC - 10) was used to identified the patients who underwent TKA from the large database $(n=7789)$. Patients who had undergone revision hip and/or knee arthroplasty or bilateral TKA, with metastatic and/or bone cancer, with lower-extremity fractures, younger than 18 years, with bleeding diathesis, and received an autologous blood transfusion rather than an allogeneic blood product were excluded according to their electronic medical records $(n=1464)$. Finally, 6325 patients were included in this study, including $4902(77.50 \%)$ patients for whom a tourniquet was used during the TKA procedure and $1423(22.50 \%)$ patients who did not have a tourniquet applied. Tourniquet was used before skin incision for 4531 patients, while before placing the prosthesis for the remaining 371 patients in tourniquet use group. And the pressure of tourniquet was determined by the leader of each medical team. All the operations were performed under the supervision of the medical team leaders, chief surgeons or associate chief surgeons come from GradeA Tertiary Hospital. The demographic characteristics, which including age, sex, body mass index (BMI), and diagnoses, comorbidities which including hypertension, diabetes, coronary heart disease, and chronic obstructive pulmonary diseases, preoperative drug use, results of preoperative laboratory examination, operative variables, such as anesthesia methods, American Society of Anesthesiologists (ASA) class, TXA use applicated intravenously or intravenously combined with locally, drain use, intraoperative blood loss and operative time of the included patients who underwent primary unilateral TKA were enrolled and analyzed, and all subjects also were shown in Table 1. The total dose of TXA was $1-3 \mathrm{~g}$ for almost all of the included patients who received TXA. The drainage tubes were removed on the first day postoperatively. The first discharge diagnoses of the included patients were classified into two types: (1) degenerative arthritis (osteoarthritis) and (2) inflammatory arthritis, 
Table 1 The baseline characteristics of the patients underwent routine primary TKA

\begin{tabular}{|c|c|c|c|c|}
\hline Baseline Characteristics & No Tourniquet $(n=1423)$ & Tourniquet use $(n=4902)$ & All patients $(n=6325)$ & $P$ values \\
\hline \multicolumn{5}{|l|}{ Demographic characteristics } \\
\hline Age $(M \pm S D)$ & $66.67 \pm 8.77$ & $66.58 \pm 8.74$ & $66.60 \pm 8.75$ & 0.722 \\
\hline Female, N (\%) & 1099 (77.23\%) & $3872(78.99 \%)$ & 4971 (78.59\%) & 0.155 \\
\hline BMI & $24.89 \pm 3.56$ & $25.83 \pm 3.5 .36$ & $25.62 \pm 5.02$ & $0.000^{*}$ \\
\hline Diagnoses, N (\%) & & & & 0.145 \\
\hline $\mathrm{OA}$ & 1321 (92.83\%) & 4603 (93.90\%) & 5924 (93.66\%) & \\
\hline Inflammatory arthritis & $102(7.17 \%)$ & $299(6.10 \%)$ & $401(6.34 \%)$ & \\
\hline \multicolumn{5}{|l|}{ Comorbidities, N (\%) } \\
\hline Hypertension & $224(15.74 \%)$ & $1483(30.25 \%)$ & $1707(26.99 \%)$ & $0.000^{*}$ \\
\hline Type 2 diabetes & $51(3.58 \%)$ & $382(7.79 \%)$ & $433(6.85 \%)$ & $0.000^{*}$ \\
\hline CHD & $15(1.05 \%)$ & $202(4.13 \%)$ & $217(3.43 \%)$ & $0.000^{*}$ \\
\hline COPD & $4(0.28 \%)$ & $30(0.61 \%)$ & $34(0.54 \%)$ & 0.133 \\
\hline Preoperative analgesic use N (\%) & $241(16.94 \%)$ & $1551(31.64 \%)$ & 1792 (28.33\%) & $0.000^{*}$ \\
\hline \multicolumn{5}{|l|}{ Preoperative laboratories } \\
\hline Preoperative $\mathrm{Hb}(\mathrm{g} / \mathrm{L}$ ) & $128.54 \pm 15.24$ & $132.04 \pm 16.02$ & $131.25 \pm 15.91$ & $0.000^{*}$ \\
\hline Preoperative ALB (g/L) & $41.72 \pm 2.54$ & $40.86 \pm 2.98$ & $40.83 \pm 2.89$ & 0.095 \\
\hline \multicolumn{5}{|l|}{ Operative variables } \\
\hline Anesthesia, N (\%) & & & & $0.000^{*}$ \\
\hline General & $1271(89.32 \%)$ & $3056(62.34 \%)$ & $4327(68.41 \%)$ & \\
\hline Regional & $152(10.68 \%)$ & $1846(37.66 \%)$ & $1998(31.59 \%)$ & \\
\hline ASA class, N (\%) & & & & $0.007^{*}$ \\
\hline$<3$ & $1303(91.57 \%)$ & $4367(89.09 \%)$ & $5670(89.64 \%)$ & \\
\hline$\geq 3$ & $120(8.43 \%)$ & $535(10.91 \%)$ & $655(10.36 \%)$ & \\
\hline TXA use N (\%) & $639(44.91 \%)$ & $2758(56.26 \%)$ & $3397(53.71 \%)$ & $0.000^{*}$ \\
\hline Drain use, N (\%) & $564(39.63 \%)$ & $3976(81.11 \%)$ & 4540 (71.78\%) & $0.000^{*}$ \\
\hline Intraoperative blood loss (mL) & $168.43 \pm 100.56$ & $166.55 \pm 97.71$ & $166.97 \pm 98.36$ & 0.526 \\
\hline Operative time (min) & $81.60 \pm 27.28$ & $87.32 \pm 29.51$ & $86.03 \pm 29.12$ & $0.000^{*}$ \\
\hline
\end{tabular}

$B M I$ body mass index; OA osteoarthritis; $C H D$ coronary heart disease; COPD chronic obstructive pulmonary disease; $H b$ hemoglobin; $A L B$ albumin; $A S A$ American Society of Anesthesiologists; TXA tranexamic acid. * : $p<0.05$

which consisted of rheumatoid arthritis and ankylosing spondylitis. The ASA classification of each patient evaluated by anesthetist before surgery was divided into two class: $<3$ or class $\geq 3$. In addition, the anesthesia methods were divided into two types: general or regional anesthesia.

\section{Statistical analyses}

Continuous variables were summarized as mean \pm standard deviation, and categorical variables were presented as frequency (proportion). The correlations of the covariates enrolled in logistic and linear regression analyses were quantified using Spearman's rank correlation analysis. The crude model of transfusion rate and PLOS regarding the use of tourniquet in TKA were built using univariate analyses. Logistic and linear regression analyses were used to adjust other variables and explore the relationships between these variables. The relationship between PLOS and transfusion rate and the enrolled covariates was presented as relative risk (RR) and 95\% confidence interval $(\mathrm{CI})$, and partial regression coefficient and $95 \% \mathrm{CI}$, respectively. A value of $P<0.05$ was considered to indicate statistical significance. All data analyses were performed using SPSS version 21 software (IBM, Armonk, NY, USA).

\section{Results}

Data completeness analyses and Spearman's rank correlations between covariates

Based on comparison with data from the hospital information system, the completeness of reporting was nearly $94 \%$ for unilateral primary TKA. The portion of missing or incorrect information of enrolled variables was generally less than $0.5 \%$. Spearman's rank correlation analyses showed that the absolute value of rank correlation coefficient between covariates enrolled in logistic and linear regression analyses ranged from 0.002 to 0.278 , which indicated that correlations between the included variables were low and met the requirements of logistic and linear regression analyses Fig. 1. 


\begin{tabular}{|c|c|c|c|c|c|c|c|c|c|}
\hline & $\begin{array}{l}\text { Opera- } \\
\text { tive time }\end{array}$ & $\begin{array}{l}\text { Intra-op } \\
\text { bleeding }\end{array}$ & $\begin{array}{c}\text { Drain } \\
\text { use }\end{array}$ & TXA use & $\begin{array}{l}\text { ASA } \\
\text { class }\end{array}$ & $\begin{array}{c}\text { Anesthe- } \\
\text { sia }\end{array}$ & $\begin{array}{c}\text { Pre-op } \\
\text { ALB }\end{array}$ & $\begin{array}{l}\text { Preoper- } \\
\text { ative Hb }\end{array}$ & \\
\hline Age & 1 & 0.107 & 0.031 & -0.210 & -0.011 & 0.229 & -0.086 & 0.156 & $\begin{array}{l}\text { Opera- } \\
\text { tive time }\end{array}$ \\
\hline Gender & -0.082 & 1 & 0.019 & -0.135 & 0.068 & 0.144 & -0.028 & 0.002 & $\begin{array}{l}\text { Intra-op } \\
\text { bleeding }\end{array}$ \\
\hline BMI & 0.032 & -0.003 & 1 & 0.278 & 0.059 & 0.065 & 0.100 & -0.110 & $\begin{array}{c}\text { Drain } \\
\text { use }\end{array}$ \\
\hline Diagnos- & 0.044 & -0.251 & -0.097 & 1 & -0.103 & -0.038 & 0.217 & -0.257 & TXA use \\
\hline $\begin{array}{l}\text { Hypert-e } \\
\text { nsion }\end{array}$ & 0.026 & 0.150 & 0.131 & -0.098 & 1 & 0.013 & -0.065 & -0.047 & $\begin{array}{l}\text { ASA } \\
\text { class }\end{array}$ \\
\hline Diabetes & 0.031 & 0.072 & 0.046 & -0.040 & 0.250 & 1 & 0.064 & 0.033 & $\begin{array}{c}\text { Anesth- } \\
\text { esia }\end{array}$ \\
\hline CHD & -0.016 & 0.084 & 0.038 & -0.035 & 0.165 & 0.097 & 1 & -0.052 & $\begin{array}{l}\text { Pre-op } \\
\text { ALB }\end{array}$ \\
\hline COPD & -0.009 & 0.034 & 0.021 & -0.001 & 0.038 & 0.040 & 0.057 & 1 & $\begin{array}{l}\text { Preoper- } \\
\text { ative Hb }\end{array}$ \\
\hline $\begin{array}{c}\text { Pre-op } \\
\text { analgesic }\end{array}$ & 0.007 & -0.24 & -0.037 & 0.004 & -0.042 & -0.022 & -0.020 & 0.021 & 1 \\
\hline $\begin{array}{l}\text { Preoper- } \\
\text { ative } \mathrm{Hb}\end{array}$ & -0.029 & 0.019 & 0.015 & -0.054 & 0.029 & 0.009 & 0.020 & 0.004 & 0.053 \\
\hline $\begin{array}{c}\text { Pre-op } \\
\text { ALB }\end{array}$ & 0.045 & -0.056 & 0.066 & -0.119 & 0.055 & 0.035 & -0.018 & -0.002 & 0.040 \\
\hline $\begin{array}{l}\text { Anesth- } \\
\text { esia }\end{array}$ & -0.020 & 0.013 & 0.008 & -0.020 & 0.182 & 0.103 & 0.087 & 0.043 & 0.029 \\
\hline $\begin{array}{l}\text { ASA } \\
\text { class }\end{array}$ & -0.007 & 0.111 & -0.007 & -0.037 & 0.082 & 0.076 & 0.084 & 0.003 & 0.056 \\
\hline TXA use & 0.033 & -0.051 & 0.039 & 0.027 & -0.069 & -0.026 & -0.027 & -0.010 & 0.086 \\
\hline $\begin{array}{c}\text { Drain } \\
\text { use }\end{array}$ & 0.038 & -0.006 & 0.072 & 0.016 & 0.100 & 0.068 & 0.051 & -0.002 & 0.190 \\
\hline $\begin{array}{l}\text { Intra-op } \\
\text { bleeding }\end{array}$ & -0.024 & 0.032 & 0.006 & -0.004 & 0.116 & 0.056 & 0.047 & 0.035 & -0.091 \\
\hline \multirow[t]{2}{*}{$\begin{array}{l}\text { Opera- } \\
\text { tive time }\end{array}$} & -0.058 & -0.033 & 0.015 & -0.022 & 0.086 & 0.012 & 0.026 & 0.016 & -0.010 \\
\hline & Age & Gender & BMI & $\begin{array}{l}\text { Diagno- } \\
\text { ses }\end{array}$ & $\begin{array}{l}\text { Hypert- } \\
\text { ension }\end{array}$ & Diabetes & CHD & COPD & $\begin{array}{l}\text { Pre-op } \\
\text { analgesic }\end{array}$ \\
\hline
\end{tabular}

Fig. 1 Spearman's rank correlations between covariates enrolled in logistic and linear regression analyses. BMl: body mass index; OA: osteoarthritis; CHD: coronary heart disease; COPD: chronic obstructive pulmonary disease; Hb: hemoglobin; ALB: albumin; ASA: American Society of Anesthesiologists; TXA: tranexamic acid; Pre-op: pre-operative; Intra-op: Intra-operative

Transfusion rate and PLOS for all patients and two groups The total transfusion rate was $12.71 \%$ for all enrolled patients who underwent unilateral primary TKA, while $14.57 \%$ for the tourniquet group and $6.47 \%$ for the notourniquet group. The average PLOS was $7.41 \pm 3.57$ days for all patients after TKA, while $7.72 \pm 3.54$ days for the tourniquet group and $6.44 \pm 3.48$ days for the notourniquet group (Table 2 and Fig. 2).

Impact of tourniquet use on transfusion rate and PLOS in unilateral primary TKA

As shown in Table 3, several statistical models including different covariates were built to evaluate the influence

Table 2 The transfusion rate and postoperative length of stay in routine primary TKA

\begin{tabular}{llll}
\hline Variables & No Tourniquet $(\boldsymbol{n}=\mathbf{1 4 2 3})$ & Tourniquet use $(\boldsymbol{n}=\mathbf{4 9 0 2})$ & All $(\boldsymbol{n}=\mathbf{6 3 2 5})$ \\
\hline Transfusion N (\%) & $92(6.47 \%)$ & $712(14.52 \%)$ & $804(12.71 \%)$ \\
PLOS (days) & $6.44 \pm 3.48$ & $7.72 \pm 3.54$ & $7.41 \pm 3.57$ \\
\hline
\end{tabular}

PLOS postoperative length of stay 


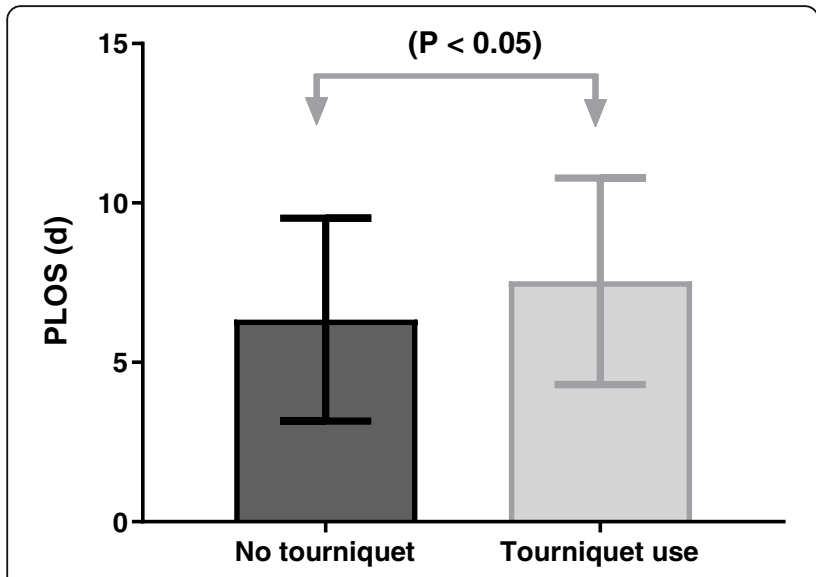

Fig. 2 The postoperative length of stay of two groups

of tourniquet use in TKA on transfusion rate and PLOS. First, univariate analyses (crude model) showed that tourniquet use in TKA was associated with a higher transfusion rate $(\mathrm{RR}=2.458,95 \% \mathrm{CI} 1.962-3.081, P<$ $0.001)$ and longer PLOS $(B=1.280,95 \%$ CI 1.066-1.494, $P<0.001)$. After adjusting for age, sex, BMI, and orthopedic diagnoses using logistic and linear regression analyses, our results showed that tourniquet application remained correlated with a higher transfusion rate $(R R=$ 2.604, 95\%CI 2.075-3.267, $P<0.001$ ) and longer PLOS $(B=1.294,95 \%$ CI 1.080-1.508, $P<0.001)$ (model 1).

After further adjustment for preoperative comorbidities (hypertension, type 2 diabetes, coronary heart disease, chronic obstructive pulmonary disease), preoperative analgesic use, and preoperative hemoglobin and albumin based on model 1, using logistic and linear regression analyses tourniquet use was still correlated with a higher transfusion rate $(\mathrm{RR}=2.319,95 \% \mathrm{CI} 1.841-$ 2.922, $P<0.001)$ and longer PLOS $(B=1.278,95 \% \mathrm{CI}$ 1.061-1.495, $P<0.001$ ) (model 2). Finally, After further controlling for all covariates (covariates in model 2 plus the operative variables including anesthesia method, ASA class, intraoperative blood loss, operative time, and TXA, and drain use), tourniquet use during unilateral primary TKA remained associated with a higher transfusion rate $(\mathrm{RR}=1.888,95 \% \mathrm{CI} 1.449-2.461, P<0.001)$ and longer PLOS $(B=0.923,95 \%$ CI $0.690-1.156, P<0.001)$, as presented in model 3 .

\section{Discussion}

By evaluating the data of 6325 patients, this study aimed to identify the impact of tourniquet use on transfusion rate and PLOS in patients undergoing primary unilateral TKA. Our findings suggested that tourniquet application during surgical procedure was correlated with a higher transfusion rate and a longer PLOS in patients who underwent unilateral primary TKA.

Although several studies have evaluated the influence of tourniquet use during TKA on blood loss and transfusion, no consensus has been reached about whether or not to use a tourniquet in routine primary TKA because of the diversity of current literature results [17]. A retrospective cohort study of 117 patients by Barros et al. [18] showed that tourniquet use in TKA resulted in a lower decrease in hemoglobin and hematocrit as well as fewer necessary blood transfusions. Surprisingly, Schnettler et al. [19] reported that tourniquet application during TKA resulted in a paradoxical increase in blood loss. Similarly, a meta-analysis of 13 randomized controlled trials (RCTs) involving 859 patients demonstrated that tourniquet use could minimize intraoperative blood loss and total blood loss, but increased postoperative total blood loss [20]. Schnettler et al. [19] suggested that increased blood loss from tourniquet use during TKA was likely the result of increased hidden blood loss (if a closed suction drain was not used), which accounts for more than half of the total blood loss, caused by the blood volume permeating through the adjacent soft tissues and joint space of the knee after the skin is closed following a surgical procedure [21]. The reason for this may be that tourniquet application augments fibrinolytic activity, which leads to increased hidden blood loss after tourniquet release [22].

For many orthopedists, reducing intraoperative blood loss, which potentially offers a relatively blood-free

Table 3 The results of logistic and liner regression analyses in routine primary TKA

\begin{tabular}{lllll}
\hline Variables & Transfusion rate & & PLOS \\
\cline { 2 - 3 } & RR (95\%Cl) & $\boldsymbol{P}$ value & B (95\%Cl) & P value \\
\hline Crude model & $2.458(1.962-3.081)$ & 0.000 & $1.280(1.066-1.494)$ & 0.000 \\
Model 1 & $2.604(2.075-3.267)$ & 0.000 & $1.294(1.080-1.508)$ & 0.000 \\
Model 2 & $2.319(1.841-2.922)$ & 0.000 & $1.278(1.061-1.495)$ & 0.000 \\
Model 3 & $1.888(1.449-2.461)$ & 0.000 & $0.923(0.690-1.156)$ & 0.000 \\
\hline
\end{tabular}

PLOS postoperative length of stay

Model 1: controlled for age, gender, body mass index and diagnoses

Model 2: controlled for model 1 + hypertension, type 2 diabetes, chronic obstructive pulmonary disease, coronary heart disease, preoperative analgesic use, hemoglobin and albumin

Model 3: controlled for model 2 + method of anesthesia, American Standards Association class, operative time, intraoperative bleeding, tranexamic acid and drain use 
operating field and tight fixation of bone cement, is a crucial reason for using a pneumatic tourniquet during TKA. However, the controlled hypotension technique, which allows TKA to proceed without a tourniquet, is increasingly being used in total joint arthroplasty (TJA) [23]. An RCT performed by Juelsgaard et al. [24] reported that controlled hypotension could not only minimize both intraoperative blood loss and TBL, but also reduce the need for blood transfusion without increasing the risk of cardiopulmonary, cerebral, or renal complications. Additionally, TXA has been more extensively used in recent years to inhibit the fibrinolytic system and reduce blood loss during TJA. An RCT performed by Huang et al. [14], which involved 150 patients who underwent TKA, revealed that tourniquet use results in no reduction in intraoperative and hidden blood loss beyond that provided by TXA alone; moreover, the patients treated with TXA without a tourniquet had better early clinical outcomes, including a lower ratio of postoperative knee swelling, less postoperative pain, and better early knee function, compared with those treated with a tourniquet during surgery [25].

Tourniquet application in TKA is associated with several adverse effects. Previous studies $[9,10]$ suggested that use of a tourniquet in TKA decreases the thigh and quadriceps muscle volumes and delays the postoperative recovery of knee function, which may be correlated with ischemia-reperfusion injury caused by a tourniquet. Several previous studies showed that ischemia-reperfusion injury in human skeletal muscle accompanied by the full release of oxygen free radicals and inflammatory cytokines could reduce protein synthesis and increase protein degradation by triggering cascades of cellular processes, which include inhibiting the protein synthesis pathway of cap-dependent translation initiation and elongation, and upregulating the ubiquitin proteasome system, one of the important pathways of skeletal muscle proteolysis [26-28]. Besides this, tourniquet use in TKA may be related to increased postoperative knee pain and swelling. A systematic review and meta-analysis of 46 RCTs demonstrated that tourniquet use in TKA caused more pain [29]. Moreover, two studies [30, 31] reported that tourniquet application in TKA was associated with a higher opioid consumption, which equates to increased pain related to tourniquet use. Liu et al. [32] demonstrated that tourniquet use in TKA hampers wound healing in the early postoperative period, indicating an association with hypoxia in the edges of the wound immediately postoperatively caused by tourniquet application. Furthermore, besides impairing the local muscle metabolism and wound healing, ischemia-reperfusion injury to the lower extremity caused by tourniquet use elevates local and systemic oxidative stress as well as inflammatory reactions and impairs renal function, especially for patients undergoing simultaneous bilateral TKA $[26,33]$.

PLOS or length of stay (LOS) is regarded as an important outcome and one of the non-substitutable markers of excellence when evaluating ERAS programs in TJA [34]. Shortening LOS/PLOS, which indicates higher hospital efficiency and productivity, is a significant target worldwide [35]. Our study revealed that tourniquet use in TKA was associated with longer PLOS, which may be caused by factors already mentioned such as compromised quadriceps muscle, increased postoperative pain and swelling, and increased postoperative blood loss. Similarly, several previous studies also showed that tourniquet application hampered functional recovery postoperatively, which also was associated with a longer PLOS [31, 36, 37].

There some limitations to this study. First, accurate pressure and duration of tourniquet application during surgical procedures was not recorded in detail in the database, and we were thus unable to evaluate the impact of different tourniquet pressures and duration times on transfusion rates and PLOS. Although some previous studies had investigated the efficiency and safety of different tourniquet pressures [38, 39] and duration times $[40,41]$ in TKA, we surmised that the disadvantages and risks associated with tourniquet use may outweigh its benefits. Second, the details of TXA and drain use were not recorded-only whether TXA and drain was used for each patient-and the schemes of TXA and drain use were different for every hospital participating in our study, which may be associated with blood loss and transfusion rates. Third, the details of the controlled hypotension technique were not recorded in our database, and the anticoagulation was not also analyzed due to the anticoagulant schemes of included patients have very large heterogeneity. Both these two variables could affect the blood loss and transfusion rates. Fourth, some important outcomes, such as the range of motion of the treated knee and the postoperative complications, were not evaluated. Even so, to our best knowledge this study includes the largest cohort of patients to date to provide conclusive results in regard to tourniquet application during TKA procedures and its impact on transfusion rate and PLOS. This study will be a useful reference for orthopedists in their decision-making process regarding routine tourniquet application in primary unilateral TKA.

\section{Conclusion}

In sum, this real-world study suggests that tourniquet use in TKA is associated with a higher transfusion rate and a longer PLOS. The impact of tourniquet use on transfusion rate and PLOS should be taken into account in clinical practice. 


\section{Abbreviations}

ASA: American Society of Anesthesiologists; Cl: confidence interval; ERAS: enhanced recovery after surgery; LOS: length of stay;

PLOS: postoperative length of stay; RCTs: randomized controlled trials; RR: relative risk; TXA: tranexamic acid; TKA: total knee arthroplasty; TJA: total joint arthroplasty

\section{Acknowledgements}

We thank Hugh McGonigle, from Edanz Group (www.edanzediting.com/ac), for editing a draft of the manuscript. We acknowledge the data entry clerk from 26 hospitals in China for their support during study period.

\section{Authors' contributions}

$H X$ and $J L Y$ : carried out study design and writing of the manuscript. JW X and $Z Y$ J: confirmed the completeness and validity of the data. Q H and GR C: participated in data collection and analysis. FX P: conceived of the study, and participated in its study design and revise of the manuscript. The author(s) read and approved the final manuscript.

\section{Funding}

This study was funded by Ministry of Health of the People's Republic of China (201302007). National Clinical Research Center for Geriatrics, West China Hospital, Sichuan University (Z2018B11).

\section{Availability of data and materials}

Please contact author for data requests.

\section{Ethics approval and consent to participate}

This study was deemed exempt by the hospital's institutional review board of Sichuan University West China hospital (2012-268). Patient consent was deemed unnecessary by each hospital's institutional review board.

\section{Consent for publication}

Not Applicable.

\section{Competing interests}

No conflict of interest exits in the submission of this manuscript, and manuscript is approved by all authors for publication.

\section{Author details}

${ }^{1}$ Department of Orthopaedic surgery and National Clinical Research Center for Geriatrics, West China Hospital, Sichuan University, No.37, Guoxue Road, Wuhou district, Chengdu 610041, China. ${ }^{2}$ College of Earth and Environmental Sciences, School of Public Health, Lanzhou University, No.222, Tian Shui Nan Lu Road, Chengguan district, Lanzhou 730000, Gansu, China. ${ }^{3}$ Department of Orthopaedic surgery, West China Hospital, Sichuan University, No.37, Guoxue Road, Wuhou district, Chengdu 610041, China.

\section{Received: 30 January 2020 Accepted: 31 August 2020}

\section{Published online: 18 September 2020}

\section{References}

1. Kehlet H. Fast-track hip and knee arthroplasty. Lancet (London, England). 2013:381(9878):1600-2

2. Beard DJ, Davies LJ, Cook JA, et al. The clinical and cost-effectiveness of total versus partial knee replacement in patients with medial compartment osteoarthritis (TOPKAT): 5-year outcomes of a randomised controlled trial. Lancet. 2019.

3. Kumar N, Yadav C, Singh S, Kumar A, Vaithlingam A, Yadav S. Evaluation of pain in bilateral total knee replacement with and without tourniquet; a prospective randomized control trial. J Clin Orthop Trauma. 2015;6(2):85-8.

4. Saied A, Ayatollahi Mousavi A, Arabnejad F, Ahmadzadeh HA. Tourniquet in surgery of the limbs: a review of history, types and complications. Iran Red Crescent Med J. 2015;17(2):e9588.

5. Alexandersson $M$, Wang $E Y$, Eriksson S. A small difference in recovery between total knee arthroplasty with and without tourniquet use the first 3 months after surgery: a randomized controlled study. Knee Surg Sports Traumatol Arthrosc. 2019;27(4):1035-42.

6. Alcelik I, Pollock RD, Sukeik M, Bettany-Saltikov J, Armstrong PM, Eimer P. A comparison of outcomes with and without a tourniquet in Total knee
Arthroplasty a systematic review and meta-analysis of randomized controlled trials. J Arthroplast. 2012;27(3):331-40.

7. Smith TO, Hing CB. Is a tourniquet beneficial in total knee replacement surgery? A meta-analysis and systematic review. Knee. 2010;17(2):141-7.

8. Dennis DA, Kittelson AJ, Yang CC, Miner TM, Kim RH, Stevens-Lapsley JE. Does tourniquet use in TKA affect recovery of lower extremity strength and function? A randomized trial. Clin Orthop Relat Res. 2016;474(1):69-77.

9. Guler $\mathrm{O}$, Mahirogullari $\mathrm{M}$, Isyar $\mathrm{M}$, et al. Comparison of quadriceps muscle volume after unilateral total knee arthroplasty with and without tourniquet use. Knee Surg Sports Traumatol Arthrosc. 2016;24(8):2595-605.

10. Dreyer HC. Tourniquet use during knee replacement surgery may contribute to muscle atrophy in older adults. Exerc Sport Sci Rev. 2016;44(2): $61-70$.

11. Degoute C-S. Controlled hypotension - a guide to drug choice. Drugs. 2007; 67(7):1053-76

12. McCormack PL. Tranexamic acid a review of its use in the treatment of Hyperfibrinolysis. Drugs. 2012;72(5):585-617.

13. Xie J, Ma J, Yao H, Yue C, Pei F. Multiple boluses of intravenous Tranexamic acid to reduce hidden blood loss after primary Total knee Arthroplasty without tourniquet: a randomized clinical trial. J Arthroplast. 2016;31(11): 2458-64.

14. Huang Z, Xie X, Li L, et al. Intravenous and topical Tranexamic acid alone are superior to tourniquet use for primary Total knee Arthroplasty: a prospective, randomized controlled trial. J Bone Joint Surg Am. 2017;99(24): 2053-61.

15. Wynell-Mayow W, Saeed MZ. Much ado about nothing: the effect of tourniquet time on an accelerated rehabilitation programme following total knee replacement (TKR). Eur J Orthop Surg Traumatol. 2018;28(6):1177-82.

16. Hasanain MS, Apostu D, Alrefaee A, Tarabichi S. Comparing the effect of tourniquet vs tourniquet-less in simultaneous bilateral Total knee Arthroplasties. J Arthroplast. 2018;33(7):2119-24.

17. F-z J, H-m Z, Y-c H, G- $f$ Z. Use of a tourniquet in total knee arthroplasty: a systematic review and meta-analysis of randomized controlled trials. J Orthop Sci. 2015:20(1):110-23.

18. Barros MFFHd, Ribeiro EJC, Dias RG. Blood level changes in total knee arthroplasty with and without a tourniquet. Rev Bras Ortop. 2017;52(6):725-30.

19. Schnettler T, Papillon $\mathrm{N}$, Rees $\mathrm{H}$. Use of a tourniquet in Total knee Arthroplasty causes a paradoxical increase in Total blood loss. J Bone Joint Surg Am. 2017;99(16):1331-6.

20. Yi S, Tan J, Chen C, Chen H, Huang W. The use of pneumatic tourniquet in total knee arthroplasty: a meta-analysis. Arch Orthop Trauma Surg. 2014 134(10):1469-76

21. Xie J, Hu Q, Ma J, Huang Q, Pei F. Multiple boluses of intravenous tranexamic acid to reduce hidden blood loss and the inflammatory response following enhanced-recovery primary total hip arthroplasty: a randomised clinical trial. Bone Joint J. 2017;99-b(11):1442-9.

22. Risberg B. The response of the FIBRINOLYTIC system in TRAUMA. Acta Chir Scand. 1985:245-71.

23. Paul JE, Ling E, Lalonde C, Thabane L. Deliberate hypotension in orthopedic surgery reduces blood loss and transfusion requirements: a meta-analysis of randomized controlled trials. Can J Anaesthesia. 2007:54(10):799-810.

24. Juelsgaard P, Larsen UT, Sorensen JV, Madsen F, Soballe K. Hypotensive epidural anesthesia in total knee replacement without tourniquet: reduced blood loss and transfusion. Reg Anesth Pain Med. 2001;26(2):105-10.

25. Brusalis CM, Bostrom MPG, Richardson SS. Has Tranexamic acid in Total knee Arthroplasty made tourniquet use obsolete? HSS J. 2018;14(3):338-40.

26. Leurcharusmee $P$, Sawaddiruk $P$, Punjasawadwong $Y$, Chattipakorn N, Chattipakorn SC. The possible pathophysiological outcomes and mechanisms of tourniquet-induced ischemia-reperfusion injury during Total knee Arthroplasty. Oxidative Med Cell Longev. 2018;2018:8087598.

27. Rasmussen LE, Holm HA, Kristensen PW, Kjaersgaard-Andersen P. Tourniquet time in total knee arthroplasty. Knee. 2018:25(2):306-13.

28. Jawhar A, Hermanns S, Ponelies N, Obertacke U, Roehl H. Tourniquetinduced ischaemia during total knee arthroplasty results in higher proteolytic activities within vastus medialis cells: a randomized clinical trial. Knee Surg Sports Traumatol Arthrosc. 2016;24(10):3313-21.

29. Liu Y, Si H, Zeng Y, Li M, Xie H, Shen B. More pain and slower functional recovery when a tourniquet is used during total knee arthroplasty. Knee Surg Sports Traumatol Arthrosc. 2019;28(6):1842.

30. Bakker SMK, Kosse NM, Crnic S, Scheer G-J, Stienstra R. Influence of a tourniquet on opioid consumption after local infiltration analgesia for Total 
knee Arthroplasty. Turkish J Anaesthesiology Reanimation. 2019;47(2):10711.

31. Ejaz A, Laursen AC, Kappel A, et al. Faster recovery without the use of a tourniquet in total knee arthroplasty. Acta Orthop. 2014;85(4):422-6.

32. Liu P-L, Li D-Q, Zhang Y-K, Lu Q-S, Ma L, Bao X-Z. Influence of tourniquet on wound healing in total knee arthroplasty: a randomized and paired clinical trial. Int J Clin Exp Med. 2017;10(2):3653-60.

33. Yang $\mathrm{X}-\mathrm{h}$, Wang $\mathrm{Y}-\mathrm{h}$, Wang $\mathrm{J}-\mathrm{j}$, et al. Role of angiotensin-converting enzyme (ACE and ACE2) imbalance on tourniquet-induced remote kidney injury in a mouse hindlimb ischemia-reperfusion model. Peptides. 2012;36(1):60-70.

34. Kehlet $\mathrm{H}$, Wilmore DW. Multimodal strategies to improve surgical outcome. Am J Surg. 2002;183(6):630-41.

35. Morton J, Anastassopoulos KP, Patel ST, et al. Frequency and outcomes of blood products transfusion across procedures and clinical conditions warranting inpatient care: an analysis of the 2004 healthcare cost and utilization project nationwide inpatient sample database. Am J Med Qual. 2010;25(4):289-96.

36. Zhou K, Ling T, Wang $H$, et al. Influence of tourniquet use in primary total knee arthroplasty with drainage: a prospective randomised controlled trial. $J$ Orthop Surg Res. 2017;12:1

37. Yin D, Delisle J, Banica A, et al. Tourniquet and closed-suction drains in total knee arthroplasty. No beneficial effects on bleeding management and knee function at a higher cost. Orthop Traumatol Surg Res. 2017;103(4):583-9.

38. Kim TK, Bamne AB, Sim JA, Park JH, Na YG. Is lower tourniquet pressure during total knee arthroplasty effective? A prospective randomized controlled trial. BMC Musculoskelet Disord. 2019;20(1):275.

39. Tuncali B, Boya H, Kayhan Z, Arac S. Tourniquet pressure settings based on limb occlusion pressure determination or arterial occlusion pressure estimation in total knee arthroplasty? A prospective, randomized, double blind trial. Acta Orthop Traumatol Turc. 2018;52(4):256-60.

40. Wang $\mathrm{K}, \mathrm{Ni} \mathrm{S}$, Li Z, et al. The effects of tourniquet use in total knee arthroplasty: a randomized, controlled trial. Knee Surg Sports Traumatol Arthrosc. 2017;25(9):2849-57.

41. Wang C, Zhou C, Qu H, Yan S, Pan Z. Comparison of tourniquet application only during cementation and long-duration tourniquet application in total knee arthroplasty: a meta-analysis. J Orthop Surg Res. 2018;13(1):216.

\section{Publisher's Note}

Springer Nature remains neutral with regard to jurisdictional claims in published maps and institutional affiliations.

Ready to submit your research? Choose BMC and benefit from:

- fast, convenient online submission

- thorough peer review by experienced researchers in your field

- rapid publication on acceptance

- support for research data, including large and complex data types

- gold Open Access which fosters wider collaboration and increased citations

- maximum visibility for your research: over $100 \mathrm{M}$ website views per year

At $\mathrm{BMC}$, research is always in progress.

Learn more biomedcentral.com/submissions 